\title{
ON THE ALLEGED ASSOCIATION BETWEEN EXTREMELY LOW FREQUENCY MAGNETIC FIELD EXPOSURES AND AN INCREASED RISK OF ALZHEIMER'S DISEASE *
}

\author{
A. Maes 1, R. Anthonissen 1, L. Verschaeve ${ }^{* *} 1,2$ \\ ${ }^{1}$ Scientific Institute of Public Health, Toxicology Section, Brussels, Belgium \\ ${ }^{2}$ University of Antwerp, Department of Biomedical Sciences, Antwerp, Belgium
}

\begin{abstract}
There are a few publications in scientific journals suggesting that persons who are regularly exposed to ELF-magnetic fields (occupational, but also residential exposures) may be at risk for contracting Alzheimer's disease. It should be noted that these reports are only pointing to a possible association but do not at present provide any proof of association. We have performed a number of preliminary in vitro laboratory investigations to explore the plausibility of such an association. Our investigations were based on similarities found in cells from Alzheimer disease patients and in cells exposed to extreme low frequency magnetic fields. We especially investigated genetic damage in $\mathrm{C}_{3} \mathrm{~A}$ and $\mathrm{SH}_{-} \mathrm{SY}_{5} \mathrm{Y}$ cells exposed in vitro to $5 \mathrm{O} \mathrm{Hz}$ magnetic fields (o-5OO $\left.\mu \mathrm{T}\right)$ using the cytome assay. We found an increased frequency of large micronuclei (suggesting a possible aneugenic effect) and increased frequency of nuclear buds (suggesting gene amplification). In this, our results may show some similarities with the observed micronuclei in blood and buccal cells of Alzheimer disease patients. The effects were found in both cell lines and were previously observed for exposure levels as low as $10 \mu T$. This is however in contrast with earlier results obtained in human lymphocytes where no induction of micronuclei was found using the same exposure unit. The results thus need to be confirmed and further analyses need to be done.
\end{abstract}

Key words: Alzheimer's disease, magnetic fields, $\mathrm{C}_{3} \mathrm{~A}$ cells, $\mathrm{SH}-\mathrm{SY}_{5} \mathrm{~T}$ cells, Vitotox test, cytome assay

DOI: $10.21175 /$ RadJ.2016.02.028

\section{INTRODUCTION}

Some reports have linked professional exposure to ELF-magnetic fields (MFs) with an increased risk of Alzheimer's disease (AD) [1-8]. A Swiss study also found a relationship between residential magnetic field exposure from power lines and mortality from such neurodegenerative conditions [9]. Other studies followed but at present they are not conclusive yet and further research is needed [10,11]. Our objectives were to search for experimental evidence that may or may not support the alleged association between ELF-magnetic field exposure and $\mathrm{AD}$.

For this purpose we previously conducted a literature review [11] which revealed a number of similarities but also dissimilarities between $\mathrm{AD}$ and ELF exposed cells or organisms (Table 1). We in particular focused on the genetic effects where it was shown that:

-Alzheimer's disease is characterized by a number of genetic events which may result in aneuploidy of particularly chromosomes 17 and 21 .

-ELF-MF's may possibly directly or indirectly (e.g., as a co-mutagen) induce genetic events as those found in Alzheimer's disease and therefore be responsible for an increased risk of this disease.

The latter is rather speculative. Given the level of energy involved, a direct alteration of the ELF- magnetic fields with genomic structures is difficult to consider. Therefore, there is a general consensus that ELF-MF's, especially at normal (moderate) exposure levels are not directly mutagenic $[19,20]$. Some papers yet suggest that ELF-MF's may make naturally-occurring free radicals available to interact with DNA, and that electric fields within tissues can possibly disrupt cellular processes and cause DNA damage in an indirect way. It is theoretically also possible that these fields can influence the incidence of aneuploidy synergistically. Effects were for example found when ELF's were used as cofactors that modify cellular responses to other agents, e.g. static fields [21], benzopyrene [22], benzene [23], vinblastine [24,25], and X-rays [25]. According to these studies ELF-magnetic fields are thus able to enhance, but not to start a mutagenic (DNA damaging) effect. The latter three examples are on increased aneuploidy and therefore of particular interest for the present research. It seems obvious that ELF and aneuploidy should be further investigated so as to see whether $\mathrm{AD}$-related aneuploidies/trisomies are also induced by electromagnetic fields. At least according to some of the above mentioned papers EMF exposure may be able to promote the occurrence of aneuploidy caused by an aneugen via a mechanism involving the neuroendocrine system.

That the physiological state of the cells and cell type may be important in the occurrence or absence of ELF-effects was illustrated by Cadossi et al. [26]

\footnotetext{
* The paper was presented at the Third International Conference on Radiation and Applications in Various Fields of Research (RAD 2015), Budva, Montenegro, 2015.
} 
and Scarfi et al. [27]. It was shown that cells from aged donors and leukemic patients do respond contrary to 'other' cells [26] and that DNA damage was found in cells from Turner syndrome patients but not in healthy individuals [27].

DNA damage was also found in vivo in rat brain cells by Lai and Singh $[28,29]$, Svendenstål et al. [30,31] and Verschaeve and Maes (unpublished) showing that brain cells can be a possible target for genetic changes. Yokus et al. [32] found increased oxidative DNA damage in the plasma of rats and Udroiu et al. [33] increased aneuploidy in liver and blood cells of mice exposed to $50 \mathrm{~Hz}$ electromagnetic fields.

Table 1. Some comparisons between observations in Alzheimer's disease patients and ELF-magnetic field exposed cells or organisms

\begin{tabular}{|l|c|}
\hline Alzheimer's disease & $\begin{array}{c}\text { ELF-magnetic field } \\
\text { exposures }\end{array}$ \\
\hline Amyloid- $\beta \uparrow$ & $\uparrow[12,13]$ \\
\hline Melatonin $\downarrow$ & $?[14]$ \\
\hline $\begin{array}{l}\text { acetylcholine deficit in } \\
\text { brain tissues }\end{array}$ & $\begin{array}{c}\text { ? but rather the opposite } \\
\text { according to some } \\
\text { studies [15-17] }\end{array}$ \\
\hline $\begin{array}{l}\text { DNA damage } \uparrow \\
\text { Micronuclei } \uparrow \\
\text { Aneuploïdy, trisomy } \uparrow \\
\text { Gene amplification } \uparrow\end{array}$ & $\begin{array}{c}\text { Possibly co-mutagenic (also } \\
\text { with respect to aneuploïdy) } \\
{[18,19]}\end{array}$ \\
\hline
\end{tabular}

These results show that ELF magnetic fields may, possibly in conjunction with (an)other agent(s), be associated with particular chromosome instabilities. Maybe they have the same nature as those found in cells of Alzheimer disease patients. Hence it is worthwhile being further investigated.

We have performed a number of in vitro genotoxicity tests aimed at investigating whether ELF-MF's do have co-mutagenic properties and may induce effects as seen in AD patients, i.e. aneuploidy (cell division disturbances) and gene amplification. It should yet be realized that such effects do not prove the relationship between ELF-MF exposure and the disease. They only show that there are some similarities that merit further attention.

\section{INVESTIGATIONS OF POTENTIAL DIRECT AND INDIRECT GENETIC EFFECTS IN CELLS EXPOSED TO ELF-MF's}

\subsection{Exposure unit}

Cells were exposed to the MF's in a cylindrical exposure unit (380-turn coil, $42 \mathrm{~cm}$ long, $20 \mathrm{~cm}$ inner diameter). A detailed description of this exposure unit is given in Maes et al. [34]. Control measurements have revealed that the field is not perfectly sinusoidal and contains $50 \mathrm{~Hz}(100 \%)$ as well as harmonics (10\% at 250 and $350 \mathrm{~Hz}$ and $5 \%$ at 550 and $650 \mathrm{~Hz}$ ). The temperature within the coil remained unchanged during the entire exposure time $\left(37^{\circ} \mathrm{C} \pm 0.5\right)$.

\subsection{Co-mutagenic effect of ELF-MF's}

We previously reported on a co-exposure investigation using the bacterial Vitotox test [35]. This test uses two strains of engineered (TA104) Salmonella typhimurium bacteria. It is based on SOS-induction and light emission following DNA damage [36]. Bacteria were exposed for 1 and $2 \mathrm{~h}$ to magnetic fields of 100 and $500 \mu \mathrm{T}$ in conjunction with the chemicals resorcinol, bleomycin, 4nitroquinoline-oxide (-S9) and benzo[a]pyrene $(+$ S9). We did not find any indication of an ELFMF's induced co-mutagenic effect.

\subsection{Genotoxic effect of ELF-MF's investigated by the cytome assay}

We also used the cytome assay in $\mathrm{C}_{3} \mathrm{~A}$ (liver) and $\mathrm{SH}_{-} \mathrm{SY}_{5} \mathrm{Y}$ (neural) cells. In this assay we particularly paid attention to the presence of micronuclei (indicating structural or numerical chromosome aberrations), nuclear buds (gene amplification) and nucleoplasmic bridges (dicentric chromosomes). The Kastenbaum \& Bowman tables [37] were used for determining statistically significant deviations in aberration frequencies from exposed cells compared to (unexposed) control cells. This binomial test was found adequate for the purpose of this investigation. We found an increased frequency of especially large micronuclei (suggesting aneuploidy) and nuclear buds (gene amplification) in both cell lines which were statistically significant at all investigated field strengths ( $\mathrm{p}<0.05$ at $10 \mu \mathrm{T}$ and $\mathrm{p}<0.001$ at $\geq 50 \mu \mathrm{T}$ ). Figure 1 gives an example for micronuclei in $\mathrm{C}_{3} \mathrm{~A}$ cells.

ratio ELF-MF/controls

(2000 binucleated cells/exposure)

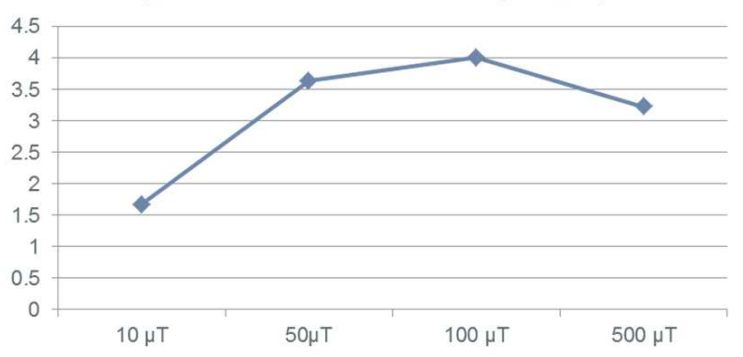

Figure 1. Micronucleus frequencies in $\mathrm{C}_{3} \mathrm{~A}$ cells following a 24h exposure to ELF-MF's (10-500 $\mu \mathrm{T})$

\section{DISCUSSION}

We did not find any co-mutagenic effect with the Vitotox test. This is somewhat in contradiction with some of the earlier reported data. It should however be realized that the Vitotox test is an indicator test which correlates well with the Ames assay (a bacterial gene mutation test) and that previously 
reported effects concern other cells and endpoints. In the Vitotox test the test organism is a bacterium which lacks, amongst others, a spindle apparatus. Therefore the Vitotox test is unable to evaluate potential aneugenic properties and hence previous studies reporting directly or indirectly ELF-MF'sinduced aneuploidy are different but not in contradiction with the Vitotox data.

On the contrary, the cytome assay provided findings that show similarities with observed micronuclei in blood and buccal cells of Alzheimer disease patients [38,39]. A replication study is not completely terminated but as far as we can tell at present the results appear to be largely identical. It should be realized yet that ELF-MF's-induced micronuclei (possibly due to aneuploidy) were not found in one of our earlier studies [24] as well as in some other investigations [19]. An explanation may be that cells that are not in optimal condition are more susceptible to ELF-MF-induced genetic alterations. This was already suggested above $[26,27]$. Our previous investigation where ELF-MF's up to $800 \mu \mathrm{T}$ did not increase the micronucleus frequency was on normal and 'healthy' human peripheral blood lymphocytes whereas the present investigation was on cell lines derived from human tumors which have an abnormal karyotype and behavior.

So far this study does not prove anything but indicates yet that further and more in depth research on ELF-MF-induced cytogenetic damage (especially aneuploidy) is justified. Such studies may give more information on the possible relationship between ELF-MF exposure and neurodegenerative diseases.

Acknowledgement: The paper is part of the research which is performed within the activities of the Belgian BioElectroMagnetics Group (BBEMG). Financial support from ELIA is acknowledged.

\section{REFERENCES}

1. E. Sobel et al., "Occupations with exposure to electromagnetic fields: a possible risk factor . for Alzheimer's disease", Am. J. Epidemiol., vol. 142, pp. 515-524, 1995.

2. E. Sobel, M. Dunn, Z. Davanipour, Z. Qian and H.C.Chui, "Elevated risk of Alzheimer's disease among workers with likely electromagnetic field exposure", Neurology, vol. 47, pp. 1477-1481, 1996.

3. E. Sobel and Z Davanipour, "Electromagnetic field exposure may cause increased production of amyloid beta and eventually lead to Alzheimer's disease", Neurology, vol. 47, pp. 1594-1600, 1996.

4. A.B. Graves, D. Rosner, D. Echeverria, M. Yost and E.B. Larson, "Occupational exposure to electromagnetic fields and Alzheimer disease", Alzheimer Dis. Assoc. Disord., vol. 13, pp. 165-170, 1999.

5. C. Qiu, L. Fratiglioni, A. Karp, B. Winblad and T. Bellander, "Occupational exposure to electromagnetic fields and risk of Alzheimer's disease", Epidemiology, vol. 15, pp. 687-694, 2004.

6. Z. Davanipour, C.C. Tseng, P.J. Lee and E. Sobel, "A case-control study of occupational magnetic field exposure and Alzheimer's disease: results from the California Alzheimer's Disease Diagnosis and Treatment Centers", BMC Neurol., vol. 7:13, 2007.

7. T. Sorahan and L. Kheifets, "Mortality from Alzheimer's, motor neuron and Parkinson's disease in relation to magnetic field exposure: findings from the study of UK electricity generation and transmission workers, 1973-2004", Occup. Environ. Med., vol. 64, pp.820-826, 2007.

8. A.M. García, A. Sisternas and S.P. Hoyos, "Occupational exposure to extremely low frequency electric and magnetic fields and Alzheimer disease: a meta-analysis", Int. J. Epidemiol., vol. 37, pp. 329$340,2008$.

9. A. Huss, A. Spoerri, M. Egger and M. Röösli, "Swiss National Cohort Study. Residence near power lines and mortality from neurodegenerative diseases: longitudinal study of the Swiss population", Am. J. Epidemiol., vol. 169, pp. 167-175, 2009.

10. M. Röösli, "Commentary: Epidemiological research on extremely low frequency magnetic fields and Alzheimer's disease--biased or informative?”, Int. J. Epidemiol., vol. 37, pp. 341-343, 2008.

11. A. Maes and L. Verschaeve, "Can cytogenetics explain the possible association between exposure to extreme low frequency magnetic fields and Alzheimer's disease?”, J. Appl. Toxicol., vol. 32, pp. 81-87, 2012.

12. E Del Giudice et al., "Fifty Hertz electromagnetic field exposure stimulates secretion of beta-amyloid peptide in cultured human neuroglioma", Neurosci Lett., vol. 418, pp. 9-12, 2007.

13. D.P. Jiang et al., "Electromagnetic pulse exposure induces overexpression of beta amyloid protein in rats", Arch. Med. Res., vol. 44, pp. 178-184, 2013.

14. Y. Touitou and B. Selmaoui, "The effects of extremely low-frequency magnetic fields on melatonin and cortisol, two marker rhythms of the circadian system", Dialogues Clin. Neurosci., vol. 14, pp. 381-399, 2012.

15. A. Afrasiabi et al., "Synaptosomal acetylcholinesterase activity variation pattern in the presence of electromagnetic fields", Int. J. Biol. Macromol., vol. 65, pp. 8-15, 2014.

16. S. Stegemann, K. Altman, H. Mühlensiepen and L.E. Feinendegen, "Influence of a stationary magnetic field on acetylcholinesterase in murine bone marrow cells", Radiat. Environ. Biophys., vol. 32, pp. 65-72, 1993.

17. K.R. Rajeswari, M. Satyanarayana, P.V. Narayan and S. Subrahmanyam, "Effect of extremely low frequency magnetic field on serum cholinesterase in humans and animals", Indian J. Exp. Biol., vol. 23, pp. 194-197, 1985.

18. J.B. Mailhes, D. Young, A.A. Marino and S.N. London, "Electromagnetic fields enhance chemicallyinduced hyperploidy in mammalian oocytes", Mutagenesis, vol.12, pp. 347-351, 1997.

19. U. Bergqvist et al., "Review of experimental investigations of EMF biological effects (o-10o kHz) ICNIRP Standing committee II", in Exposure to static and low frequency electromagnetic fields, biological effects and health consequences, R. Matthes, A. McKinley, J. Bernhardt, P.Vecchia and B. Veyret, Eds. ICNIRP13/2003, 2003, pp. 121-398.

20. Vijayalaxmi and TJ. Prihoda, "Genetic damage in mammalian somatic cells exposed to extremely low frequency electromagnetic fields: A meta-analysis of 
data from 87 publications (1990-2007)", Int. J. Radiat. Biol., vol. 85, pp. 196-213, 2009.

21. S. Tofani, A. Ferrara, L. Anglesio and G. Gilli, "Evidence for genotoxic effects of resonant ELF magnetic fields", Bioelectrochem. Bioenerg., vol. 36, pp. 9-13, 1995.

22. Y.H. Cho and H.W. Chung, "The effect of extremely low frequency electromagnetic fields (ELF-EMF) on the frequency of micronuclei and sister chromatid exchange in human lymphocytes induced by benzo(a)pyrene", Toxicol. Lett., vol. 143, pp. 37-44, 2003.

23. M. Moretti et al., "Effects of co-exposure to extremely low frequency (ELF) magnetic fields and benzene or benzene metabolites determined in vitro by the alkaline comet assay", Toxicol. Lett., vol. 157, pp. 119128, 2005.

24. G. Verheyen, G. Pauwels, L. Verschaeve and G. Schoeters, "The effect of co-exposure of $50 \mathrm{~Hz}$ magnetic fields and an aneugen on human lymphocytes, determined by the cytokinesis-block micronucleus assay", Bioelectromagnetics, vol. 24, pp. 160-164, 2003.

25. G.R. Ding, T. Nakahara and J. Miyakoshi, "Induction of kinetochore-positive and kinetochore-negative micronuclei in CHO cells by ELF magnetic fields and/or X-rays", Mutagenesis, vol. 18, pp. 439-443, 2003

26. R. Cadossi et al. "Lymphocytes and low-frequency electromagnetic fields", FASEB J., vol. 6, pp. 26672674, 1992.

27. M.R. Scarfi et al., "Cytogenetic effects induced by extremely low frequency pulsed magnetic fields in lymphocytes from Turner's syndrome subjects", Bioelectrochem. Bioenergetics, vol. 43, pp. 221-226, 1997.

28. H. Lai and N.P. Singh, "Acute exposure to a $60 \mathrm{~Hz}$ magnetic field increases DNA strand breaks in rat brain cells", Bioelectromagnetics, vol. 18, pp. 156-165, 1997.

29. H. Lai and N.P. Singh, "Magnetic-field-induced DNA strand breaks in brain cells of the rat", Environ. Health Perspect, vol. 112, pp. 687-694, 2004.
30. B.M. Svedenstål, K.J. Johanson, M.O. Mattsson and L.E. Paulsson, "DNA damage, cell kinetics and ODC activities studied in CBA mice exposed to electromagnetic fields generated by transmission lines", In Vivo, vol. 13, pp. 507-513, 1999.

31. B.M. Svedenstål, K.J. Johanson and H.H. Mild, "DNA damage induced in brain cells of CBA mice exposed to magnetic fields", In Vivo, vol. 13, pp. 551-552, 1999.

32. B. Yokus, D.U. Cakir, M.Z. Akdag, C. Sert and N. Mete, "Oxidative DNA damage in rats exposed to extremely low frequency electro magnetic fields", Free Radic. Res., vol. 39, pp. 317-323, 2005.

33. Udroiu, M. Cristaldi, L.A. Ieradi, A. Bedini, L. Giuliani and C. Tanzarella, "Clastogenicity and aneuploidy in newborn and adult mice exposed to $50 \mathrm{~Hz}$ magnetic fields”, Int. J. Radiat. Biol., vol. 82, pp. 561-517, 2006.

34. A. Maes, M. Collier, S. Vandoninck, P. Scarpa and L. Verschaeve, "Cytogenetic effects of $50 \mathrm{~Hz}$ magnetic fields of different magnetic flux densities", Bioelectromagnetics, vol. 21, pp. 589-596, 2000.

35. L. Verschaeve et al., "Genotoxicity investigation of ELF-magnetic fields in Salmonella typhimurium with the sensitive SOS-based VITOTOX test", Bioelectromagnetics, vol. 32, pp. 580-584, 2011.

36. L. Verschaeve, "High-throughput bacterial mutagenicity testing: Vitotox ${ }^{\mathrm{TM}}$ assay", in High Throughput Screening Methods in Toxicity Testing, P. Steinberg, Ed. Wiley, Publ., 2013, pp. 213-232.

37. M.A. Kastenbaum and K. O. Bowman, "Tables for determining the statistical significance of mutation frequencies", Mutat. Res., vol. 9, pp. 527-549, 1970.

38. P. Thomas and M. Fenech, "A review of genome mutation and Alzheimer's disease", Mutagenesis, vol. 22, pp. 15-33, 2007.

39. P. Thomas and M. Fenech, "Chromosome 17 and 21 aneuploidy in buccal cells is increased with ageing and in Alzheimer's disease", Mutagenesis, vol. 23, pp. 5765, 2008. 